\title{
Genetic aspects of seed longevity in barley
}

\author{
Shvachko N.A. ${ }^{1 *}$, Gerasimova T.V. ${ }^{1}$, Khlestkina E.K. ${ }^{1,2}$ \\ ${ }^{1}$ N.I. Vavilov All-Russian Institute of Plant Genetic Resources, St. Petersburg, Russia \\ ${ }^{2}$ Institute of Cytology and Genetics, SB RAS, Novosibirsk, Russia \\ *e-mail:n.shvachko@vir.nw.ru
}

Key words: seed, longevity, germination, aging, QTL, gene mapping, Hordeum

Motivation and Aim: Seed longevity is a famous factor for conservation of genetic resources and biodiversity. The maintenance of viability during storage is an important trait of agriculture crops including barley (Hordeum vulgare L.). This feature is impaired by reactive oxygen species (ROS) during seed storage and germination. Longevity of the germplasm in seed banks remains for a limited time in storage. The aim of this analysis was the detection of new candidate genes associated with seed longevity in barley according to Scopus database.

Methods and Algorithms: The development of DNA-markers was made on the basis of known allelic differences of the genes putatively related with seed longevity. The BLAST-search and annotation of nucleotide sequences of the target genes was carried out in IPK BLAST Server according to known genes of Zea mays, Oryza sativa and Arabidopsis thaliana. Seed viability tests were performed on $>90$ barley accessions maintained in VIR Genbank since 1977 using method described [1].

Results: Genetic variability among barley accessions was revealed for viability level of the seeds maintained since 1977 in Genbank cold storage. Based on the known data about relation of seed longevity with major QTLs on barley chromosomes $2 \mathrm{H}, 5 \mathrm{H}$ and $7 \mathrm{H} \mathrm{[2],} \mathrm{coincided} \mathrm{with} \mathrm{location} \mathrm{of} \mathrm{the} \mathrm{genes} \mathrm{Zeol} \mathrm{(compact} \mathrm{spikes} \mathrm{with} \mathrm{long} \mathrm{awns),} \mathrm{Ale}$ (barley vacuolar thiol protease) and nud (naked caryopsis) respectively, we estimated correlation of seed longevity with allelic state of the genes Zeol, Ale and nud. In addition, we performed in silico analysis of the genes families for glutathione synthase and glutathione reductase, since glutathione disulfide accumulation is associated with oxidative response mechanism, oxidative stress and programmed cell death seeds [3]. Conclusion: Correlation of some allelic variants in the candidate genes with barley seed longevity is established. Accessions with high seed viability not explained by known genes will be used for genetic dissection aimed on finding novel genes underlying longevity.

\section{References}

1. Khoroshaylov N.G. (Ed.). Metodicheskie ukazaniya po dlitel'nomu khraneniyu semyan [Guidelines for long-term seed storage]. Leningrad, 1981 (in Russian).

2. Nagel M., Vogel H., Landjeva S., Buck-Sorlin G., Lohwasser U., Scholz U., Börner A. Seed conservation in ex situ genebanks - genetic studies on longevity in barley. Euphytica. 2009;170(1-2):5-14.

3. Rouhier N., Lemaire S.D., Jacquot J. The role of glutathione in photosynthetic organisms: emerging functions for glutaredoxins and glutathionylation. Ann. Review Plant Biol. 2008;59(1):143-166. 